\title{
Outside the school: A review of the non-formal short-term architectural workshops
}

\author{
Işıl Ruhi Sipahioğlu* \\ Günsu Merin Abbas** ${ }^{*}$ \\ Burçin Y1lmaz ${ }^{* * *}(\mathbb{C})$
}

\begin{abstract}
Over the last fifteen years, apart from compulsory curricular studios, extracurricular intensive studios in architectural design (ISAD) have become a mainstream educational environment worldwide. ISADs cover an actual weight in non-formal architectural education. However, to date, there is no review on the methods, processes, or implementation of extracurricular ISADs. The field needs to enhance the visibility of workshop results with regular reporting of workshop activities to raise awareness among future professionals and the wider public. This review aims to make visible existing learning-teaching-experiencing environments and pedagogical conditions, practices, tendencies, and implementations in ISADs. The study follows three stages. It first conducts a scoping study to examine the research outputs on ISADs indexed in SCOPUS and Web of Science from January 1975 to September 2020 Second, it expands the workshop pool by including past ISADs reached via websites/papers. It codes each workshop with the codes and themes determined through the scoping study. Finally, it creates an interactive mapping detailing the following analysis: (1) Quantitative analysis of ISADs (Geographical distribution; outputs; principles, as elements creating the atmosphere and tactics); (2) Qualitative analysis to reveal the impact of workshop outputs on the interested stakeholders. The review suggests that ISADs, including their processes and outputs, contribute to the knowledge triangle in architecture by serving two fundamental roles: (1) A researchby-design activity to address socio-economic-ecological problems caused by the built environment; (2) A pioneering venture in improving the curriculum and practices of teaching and learning. Within the scope of the exigencies of the education field, this review uncovers the potential of ISADs in overcoming time-related, geographical, economic limitations; providing fresh perspectives on content and methods concerning architectural education; expanding the intellectual resources of students; enabling international collaboration between HEls; breeding an experimental/flexible learning and research environment in the 1st and 2 nd cycles to absorb ever-changing tools/methods promoted in professional/research sides of the field. This review provides the reader with an array of diverse teaching and learning practices on these non/informal grounds. The number of workshops included in this study is relatively small, therefore, researchers are encouraged to expand the number of workshops for further analysis.
\end{abstract}




\section{Introduction}

In architectural education, design studios are the locus where students weave their knowledge and skills gained through other formal, non-formal, and informal learning into designing (Ruhi Sipahioğlu \& Alanlı, 2020). Over the last fifteen years, apart from compulsory curricular studios, extracurricular intensive studios in architectural design (ISAD), commonly known as workshops, have become a mainstream educational environment worldwide. ISADs cover an actual weight in non-formal architectural education (Turgut \& Canturk, 2015). ${ }^{1}$ Yet, up to date, there is no overarching review on the processes and execution of extracurricular ISADs that discuss why we, including all the stakeholders, need these learning environments.

Tectonics/ways of doing/thinking of architecture face technical, aesthetic, and cultural implications of the emerging digital technologies, communication technologies, and new materialities. Architectural practices in all the fields of the discipline are thus in a reformation process. The field of education is not an exception. Except for a few notable schools, there are many limitations in architectural schools, including capacity, teaching methods, and regulatory frameworks, which hinder schools from devising changes immediately to their fixed departmental curricula (Tanyeli, 2013; Tzonis, 2014). Above all, it is now impossible to educate an all-knowing student for the diversity of architectural practices (Ruhi Sipahioğlu et al., 2020).

The formal and non-formal studios differ in several ways: The duration (a term/yearlong versus short term), requirements students must fulfill (prerequisites/mandatory versus voluntary basis without a pass-fail issue), learning environments (schools versus outside the school) (Ciravoğlu, 2003). This study suggests that these differences are what allow ISADs to be incubators for both studio models and educational practices. These incubators might absorb the challenges brought by the proliferation of new ways of thinking and making architecture.

It is true that except for a few, information about ISADs (calls for applications, studio outcomes, models) are not widely disseminated across the world. The field needs to enhance the visibility of workshop results with regular reporting of workshop activities to raise awareness among future professionals and the wider public. To this end, this scoping review addresses the following research questions: What kind of learning environments (including tools, methods, courses, curricula, context) are implemented in intensive short-term architectural design studios? What makes ISADs potent in addressing the challenges of architectural education?

The research evolved in three stages. First, it conducted a scoping study to examine the research outputs on ISADs indexed in SCOPUS and Web of Science between January 1975 and September 2020. The second section of this paper describes the review methodology, the third and fourth sections discuss the findings. The second stage expanded the pool of ISADs, by including information about previous ISADs reached through websites. It then coded each workshop with the codes and themes determined in the scoping study. At the third stage, it created an interactive mapping that illustrates the following analysis: (1) Quantitative analysis of ISADs (Geographical distribution; outputs; principles, as elements creating the atmosphere and tactics); (2) Qualitative analysis to reveal the impact of workshop outputs on the stakeholders. The fifth section covers the second and third stage results. Ultimately, this review aims to make visible existing learning-

\footnotetext{
${ }^{1}$ Current literature categorizes ISADs under informal learning. The UNESCO Institute for Lifelong Learning (UIL) (2012), which works toward the recognition, validation, and accreditation of all forms of learning, differentiates between non-formal and informal learning This difference stems from two issues. First, while non-formal learning is intentional from the learner's perspective, informal learning, in most cases, is non-intentional, or incidental. Second, non-formal learning is structured in terms of learning objectives, learning time, or learning support, informal learning is not (Yang, 2015). Hence, ISADs are non-formal learning environments.
} 
teaching-experience environments, pedagogical conditions, practices, and implementations in ISADs.

\section{Method}

\subsection{The Scoping Study}

The scoping review methodology was chosen for its aptness in providing an overview and 'mapping' of a research field without producing a summary answer to a discrete research question (Levac et al., 2010). ${ }^{2}$ This study pursued the main stages defined by Levac et al. (2010): ${ }^{3}$ (1) identifying the research question; (2) identifying relevant studies; (3) study selection; (4) charting the data; (5) collating, summarizing, and reporting the results; and (6) consultation (optional stage). The research questions given above were determined from the outset of this review.

\subsubsection{Identifying relevant studies}

To identify the relevant studies that lie at the intersection between 'architectural education,' 'workshop(s),' and 'extracurricular activities,' the study used the keywords defined in Table 1 to query two online databases, Scopus and Web of Science, from January 1975 to September 2020. These databases were chosen as they were considered the most relevant and provide the highest impact journals and conference proceedings.

Table 1 Number of records per database and searching queries

\begin{tabular}{|l|l|l|}
\hline Database & Search query (Search date: 01/10/2020) & $\begin{array}{l}\text { Number } \\
\text { of } \\
\text { records }\end{array}$ \\
\hline Scopus & $\begin{array}{l}\text { TITLE-ABS-KEY (architecture* AND education) AND TITLE-ABS-KEY (workshop) AND ( EXCLUDE ( } \\
\text { PUBYEAR, 2021 ) ) AND ( EXCLUDE ( DOCTYPE, "cr") ) AND ( EXCLUDE ( LANGUAGE, "Spanish") OR } \\
\text { EXCLUDE ( LANGUAGE, "Japanese") OR EXCLUDE ( LANGUAGE, "Portuguese" ) OR EXCLUDE ( } \\
\text { LANGUAGE, "German") ) }\end{array}$ & 411 \\
\hline $\begin{array}{l}\text { Web of } \\
\text { Science }\end{array}$ & $\begin{array}{l}\text { (AB=(architecture* AND education) AND AB=(workshop) OR AK=(architecture* AND education) AND } \\
\text { AK=(workshop) OR TI=(architecture* AND education) AND TI=(workshop) } \\
\text { Timespan: } 1975-2020 . \\
\text { Indexes: SCI-EXPANDED, SSCI, A\&HCI, CPCI-S, CPCI-SSH, BKCI-S, BKCI-SSH, ESCI. } \\
\text { LANGUAGES: (ENGLISH) }\end{array}$ & 207 \\
\hline
\end{tabular}

The study used Zotero, a bibliography management tool, to list all citations from each database and to remove 89 duplicate studies. There were 529 in total.

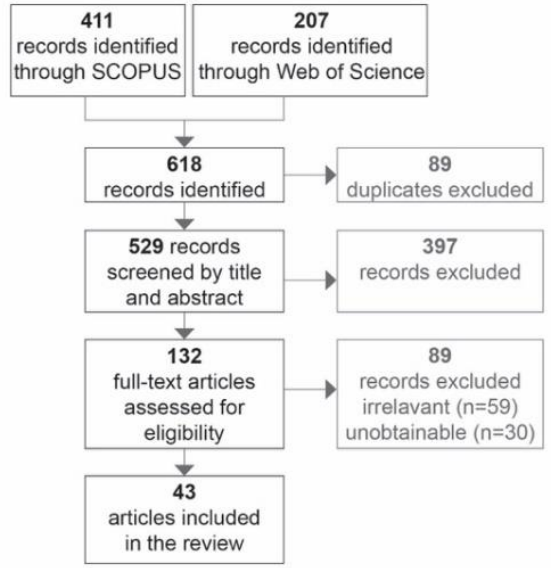

Figure 1 Search strategy and study selection process

\footnotetext{
${ }^{2}$ There exists no universal definition for this review type, including nomenclature 'scoping reviews,' 'scoping studies,' 'scoping literature reviews,' and 'scoping exercises' (Levac et al., 2010).

${ }^{3}$ For another study pursuing this method in the field of architecture, please see Ucci et al. (2015)
} 


\subsubsection{Study selection}

The study specified the exclusion and inclusion criteria based on the research questions and new familiarity with the subject upon reading the studies (Table 2).

Table 2 Inclusion and exclusion criteria

\begin{tabular}{|l|l|}
\hline We included articles that are: & We excluded articles that: \\
\hline Full text & $\begin{array}{l}\text { Conference review papers, editorial papers. } \\
\text { The full text was not available. }\end{array}$ \\
\hline Published between January 1975 and September 2020 & Were outside our search period \\
\hline Were written in English & Were of duplicated studies \\
\hline Were on short-term extracurricular architectural workshops & $\begin{array}{l}\text { No relevance to our research questions (for example, curricular } \\
\text { workshops) }\end{array}$ \\
\hline
\end{tabular}

529 studies were examined against the inclusion and exclusion criteria using the Zotero report (exclusion based on the analysis of title, abstract, and keywords). At this point, non-useful results were removed (those not listed in journal articles, workshops, or conference papers). The study excluded 397 studies, and 132 studies remained. Only studies that were clearly unrelated were removed. In case there was doubt, we took the study to the next step. We then examined the full texts of studies (filtered out 30 without a full text) and further eliminated 59 studies, ending up with 43 studies (Figure 1).

\subsubsection{Charting the data}

The study prepared a data extraction table (Table 3) for mapping the workshops based on the key research questions.

Table 3 Data extraction for each study ${ }^{4}$

\begin{tabular}{|l|l|}
\hline Extracted data & Description \\
\hline Study ID & Unique identity for the paper \\
\hline Bibliographical references & Authors, title, publication source, and publication year \\
\hline Type of paper & Book chapter, journal, conference, or workshop article \\
\hline Publication date & Publication year \\
\hline Country & Indicates the country where the workshop is organized \\
\hline Place of learning & Face-to-face or online (distance learning) \\
\hline Number of partner institutions & Indicates the number of partner organization bodies \\
\hline Partners & Name of partner organizations \\
\hline Organizing Bodies & Nature of organizing bodies (university, NGO, etc.) \\
\hline Number of students & Total number of students in the workshop \\
\hline Workshop type & Short-term workshop / winter school / summer school \\
\hline Workshop Name & The name of the workshop \\
\hline Duration of workshop & The total duration of the workshop \\
\hline Year & The year or the years the workshops are organized \\
\hline Disciplines & The major disciplines of workshops \\
\hline National / International & Indicates whether the workshop involves international or national collaboration \\
\hline Workshop focus/topic (if relevant) & \\
\hline
\end{tabular}

\subsubsection{Collating, summarizing, and reporting the results}

Scoping studies have a thematic construction to provide the breadth of the literature in three steps (Levac et al., 2010): (1) the analysis with descriptive numerical summary analysis and qualitative thematic analysis; (2) reporting the results regarding the overall research questions; (3) to emphasize how results find their place in the knowledge pool and discuss future research implications.

The first two steps are undertaken according to Braun and Clarke's (2006) six-step framework for the qualitative thematic analysis. There is no specific justification for this choice, except for its

${ }^{4}$ Appendix A (available at the online map) provides the full details of data extract. 
widespread use in social sciences. The study used qualitative data analytic software MaxQDA 2018. These steps shall not be considered a linear process, but as a more recursive process, where the analysis goes back and forth among these steps.

Table 4 Phases of thematic analysis, inspired from Braun and Clark (2006, p. 87)

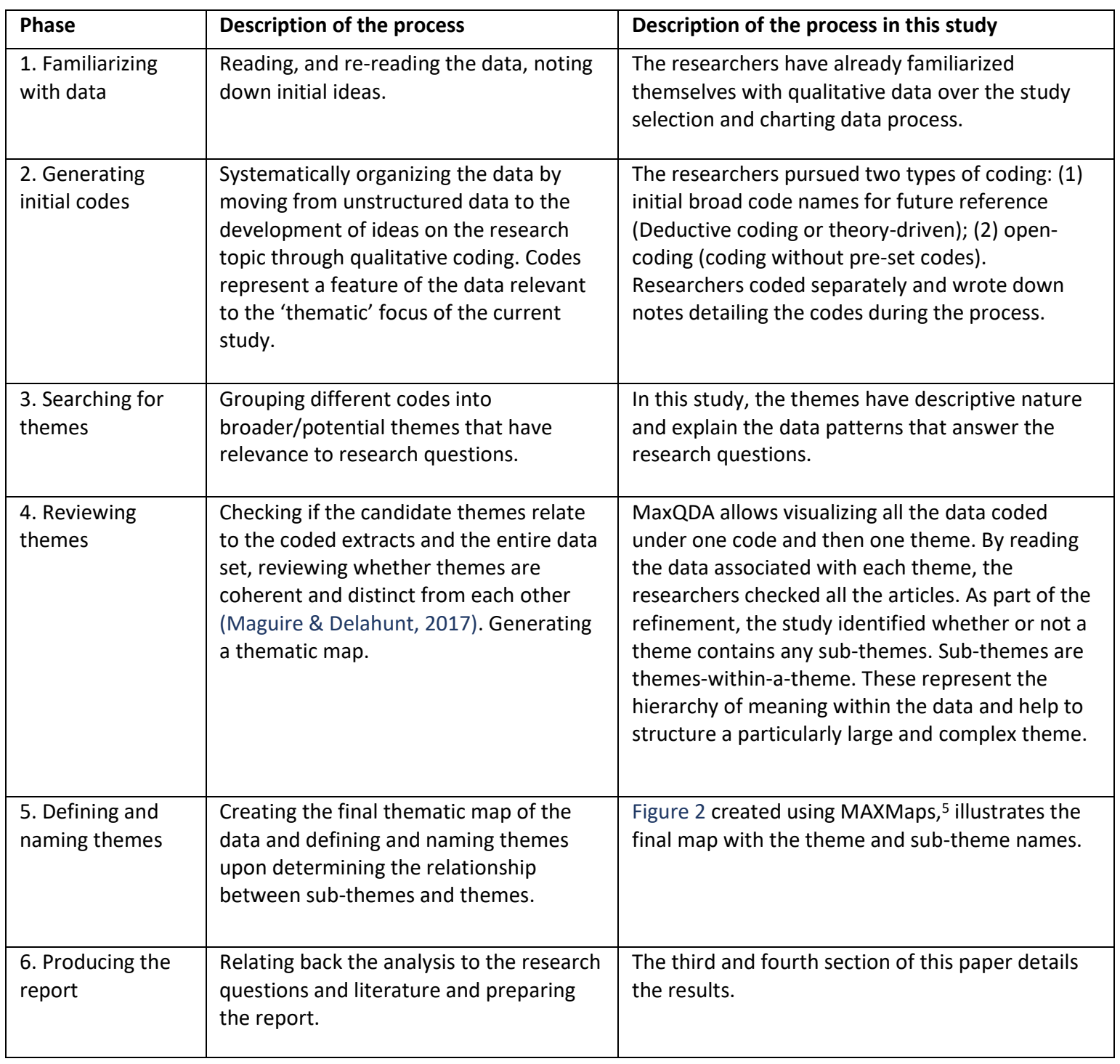

\section{ISAD Principles}

The scoping study results point out that workshops are fertile grounds for:

- intervening ongoing research, practice, or education;

- triggering future research fields;

- intervening for place-based problems;

- creating and testing alternative studio settings for formal learning;

- students to gain/enhance 'survival skills' (Sorguç et al., 2019)

There exist common tactics that create the workshop 'atmosphere' and learning practices for these fertile grounds.

${ }^{5} \mathrm{~A}$ mind-mapping tool in MaxQDA 2018. 


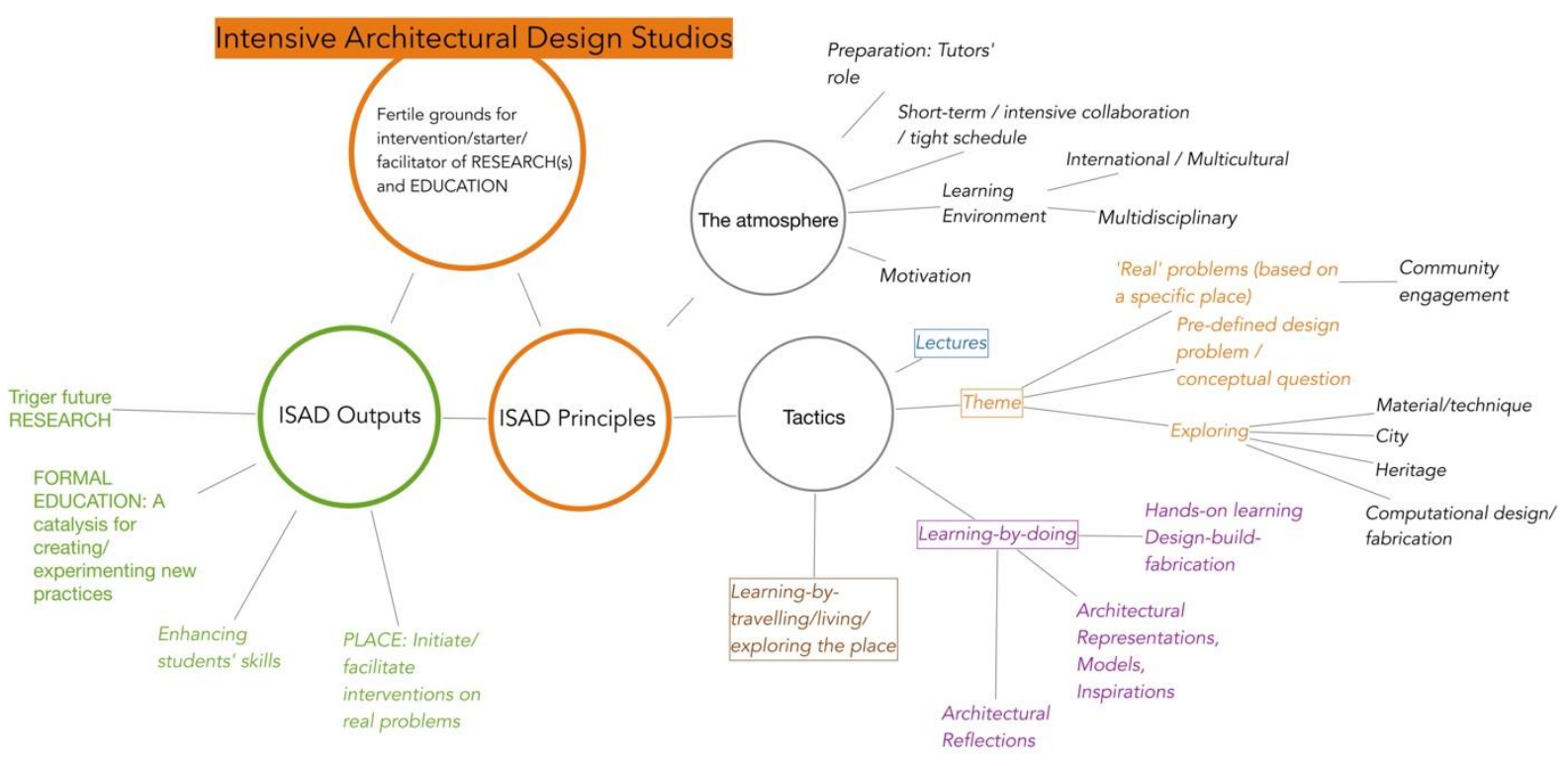

Figure 2 Representation of the relationships among emerging themes and sub-themes

\subsection{The Atmosphere}

The most crucial aspect differentiating workshops from formal settings lies in the atmosphere or ambiance that releases students from restrictions of formal processes (Orhan, 2017). Turgut and Canturk state that this "free atmosphere of workshops provides the medium for productivity and creativity of the students $(2015$, p. 89)." The common tactics for creating and supporting such a dynamic atmosphere are: (1) the preparation phase; (2) short-term/tight schedules/intensive collaboration; (3) the learning environment; (4) the motivation of tutors and students.

\subsubsection{The Preparation: The Role of Tutors and Organization Teams}

The short learning period results in difficulties in preparing assignments, the scope of lectures when compared to formal programs. This shortness necessitates a thought-through plan that enables achieving the primary objectives and overcomes possible obstacles via a flexible approach. A well-planned workshop requires significant effort in its preparation phase and places great responsibility on the workshop organization team and tutors (Garcia Saez et al., 2016; Momirski, 2019; Smatanová \& Dubovcová, 2016). Creating a good atmosphere goes beyond a logistical organization. The preparation phase includes:

- Research on learning priorities and research perspectives,

- Definition of objectives

- Assignment of tutors

- Definition of workshop theme, the main problem to solve in a particular workshop studio;

- Preparation of contents;

- Invitation of critics and/or guest lecturers (if relevant) (Milovanovic et al., 2020; Paszkowski \& Gołebiewski, 2020).

Most ISADs are open to students from diverse disciplines, hence needs, levels of experience, and individual interests. This unique student-centered atmosphere challenges tutors' to act as a facilitator, ready to be versatile to the diversity of workshop participants, for supporting experiential learning, rather than an instructor, and encouraging learning between and among all participants (Brooks-Harris \& Stock-Ward, 1999; Garcia Saez et al., 2016; Sorguç et al., 2019). Therefore, tutors hold multiple tasks and roles at the same time. 


\subsubsection{Short-Term/Tight Schedule/Intensive Collaboration}

ISADs are apt to provide an optimum period of study for students' maximum concentration, interest, and enthusiasm (Sorguç et al., 2019). This also enables keeping participants high involvement and interaction (Turgut \& Canturk, 2015). Kahvecioglu et al. state that "[l]imiting the period of workshop to 72 hours was essential in avoiding possible outside interactions and impacts of formal educational activities (2002)."

Short-term and tight schedules required collaboration in most of the reviewed workshops. Teamwork adds another level of complexity (Shatarova, 2015). The development of interpersonal skills required for teamwork is defined as one of the main objectives of workshops (Kahvecioglu et al., 2002; Smatanová \& Dubovcová, 2016; Sorguç et al., 2019). Teamwork also supports collective learning and cooperation besides broadening horizons (Polatoğlu \& Vural, 2012). For students' future practice, gaining the ability to work creatively under pressure is explained to become an essential critical skill (Paszkowski \& Gołebiewski, 2020).

Almost all the reviewed workshop tracks shared a common approach, cooperative learning that puts students in teams under conditions that stimulate teamwork skills while ensuring their accountability for the entire process. There are many debates in the field about the notion of "star architect." This notion drives architectural education in many parts of the world to focus on education for creativity. However, we observe that the profession requires professionals involved in complex collaborative and collective processes. These processes necessitate the distribution of design responsibility. In the context of education, studio teaching methods where the focus on one student's abilities and skills become problematic (Habraken, 2006; Tzonis, 2014). Previous research indicated that many architecture schools do not promote collaborative learning practices in formal design studios (Ruhi Sipahioğlu \& Alanlı, 2020). By promoting collaborative learning practices, ISADs are fertile grounds for students to gain interpersonal skills.

\subsubsection{The Learning Environment}

Organizing inter/multi-disciplinary design studios is a significant burden for fully booked departmental curricula and tight weekly/yearly schedules. Workshops are the locus for students to partake in interdisciplinary design processes (Milovanovic et al., 2020; Pereira \& Roche, 2016). Smatanová and Dubovcová state that this environment provides "a safe ground for different actors to meet (2016)."

[...] the participation of the students in this multidisciplinary meeting has enhanced their capacity for selfcriticism in several disciplines and has promoted their ability to perform learning and research strategies in an autonomous way by both interactive classes and practical exercises supervised by teachers, working individually and in groups (Tang, 2013).

Having a multidisciplinary team paves the way to assess and understand the same work from different perspectives through collective expertise and knowledge. Multidisciplinary teams are also explained to present a wide variety of concerns and interests, which assist in providing answers to a wide range of questions of varied importance (Garcia Saez et al., 2016).

Increased international diversity yields challenges (Pereira \& Roche, 2016) but benefits learners and tutors (Umran Topcu \& Taberna Torres, 2018). International workshops incorporate different cultural backgrounds. This diversity widens participants' perspectives in approaching design interventions and fosters students' working international teams' skills. As current architectural problems are globally widespread (Pereira \& Roche, 2016), in some cases, foreign professionals may discern local problems from different viewpoints while yielding a polarity of ideas (Paszkowski \& Gołebiewski, 2020). 


\title{
3.1.4 Motivation
}

In educational psychology, motivation is considered a critical factor for the success of learning. The lack of motivation has an impact on students' attention in class, hence the learning outcomes. It is maintained that "motivation to learn is directly proportional to the effectiveness of learning (Fernandez-Antolin et al., 2020)," because it stimulates students to learn and pursue learning activities. The will to delve into a specific subject correlates with students' motivation. Hence tutors need to determine the strategies that improve learning motivation (Fernandez-Antolin et al., 2020).

Existing literature details certain factors in improving learning motivation. The schedule, learning environment, and the tactics of ISADs represent diversities and this study cannot discern at this phase which factor best improve learning motivation. Almost all the reviewed articles include a common factor triggering students' motivation and informal learning. For the impact of informality, Smatanová \& Dubovcová state that:

\begin{abstract}
Informality, which aims at going beyond the normal and ordinary, provides an environment excluding the current order and rules where hierarchy is taken down. The most important benefits of informality are motivation, a communicative environment where different ideas come together, expressing oneself individually and gaining self-confidence (2016, p. 126).
\end{abstract}

A number of studies detail that international learning environments, visiting a foreign country, improving lacking skills are among the main students' motivations. For example, Sorguç et al. state that "pushing students out of their comfort zone also plays a crucial role in the self-evaluation and increase self-motivation to make up their lacking knowledge and skills (2019, p. 136)" Paszkowski and Gołębiewski (2020) explain that the competition between student groups is an additional motivational factor. Fernandez-Antolin et al. (2020) state that the use of gamification increases students' motivation.

\subsection{Tactics}

The scoping study overlays multiple tactics pursued in the reviewed workshops: (1) Lectures, (2) Themes, (3) Learning-by-doing (studio model), (4) Learning-by-travelling/living/exploring the place.

\subsubsection{Lectures}

ISADs generally include lectures prepared for the workshop themes, or if relevant, lectures for introducing participants to practical design (most often computational tools) or construction techniques.6 Lectures involve learning-by-thinking and reflecting on the theme. Invitation of external guest lecturers into formal education is considered a burden, as lecturers, especially from different disciplines, cannot give long-term commitments. Hence, workshops benefit from external lecturers, including those from diverse fields and disciplines, owing to its short-term promise (Smatanová \& Dubovcová, 2016).7

\subsubsection{Workshop Themes}

There exist different tracks in the assignment of workshop themes (1): Real problems (based on a place); (2) Pre-defined design problem / conceptual question; (3) Experimental for ongoing research; (4) Exploring (Material/Techniques; City; Heritage; Representation techniques; computational design and/or fabrication tools).

\footnotetext{
${ }^{6}$ For a workshop on unique construction material and techniques, please see (2013); for a workshop dedicated to robotic applications, please see Doyle et al. (2018).

${ }^{7}$ This paper is written during the COVID-19 outbreak at a time online lectures have become common practice. These new workshop experiences and partners' distance teaching experience have shown that guest lecturers' online seminars have become the new normal. It may be presumed that this practice will take its place shortly.
} 


\title{
3.2.2.1 'Real' problems
}

The workshop themes are 'real.' Either conceived as a hands-on studio, including the building phase, or a design studio, in these workshops, learners apply their knowledge or theory on real world problems and experiment in non-hypothetical conditions. Hence it is on the opposite side of "the abstract milieu associated with the virtual studio environment (Shatarova, 2015). International Network for Traditional Building, Architecture, and Urbanism (INTBAU) Design Workshops organized since 2002 using the charette model exemplifies this approach.8

\begin{abstract}
INTBAU's Transylvanian Village Development Workshop 2003 [...] aimed at assisting in the sustainable development of the medieval 'Saxon' villages of Transylvania. The workshop involved 32 practitioners and students from Romania and abroad, working with citizens in a 5 day charrette. Participants analysed the village and produced traditional urbanist proposals integrating heritage preservation and sustainable development. The masterplan included design guidance for simple improvements to the streetscape and amenities of the village, and for new traditional buildings in the village and in extensions to it (Hardy, 2008).
\end{abstract}

Summer Schools organized by Architecture Sans Frontiere-UK is another exemplar. ${ }^{9}$

\begin{abstract}
'Building Communities', suggests, this five-day course not only looked at the physical, construction-related aspects of improving slum neighbourhoods, but also - and perhaps more importantly - introduced the participants to the wider picture of encouraging positive change and regeneration by addressing key issues such as participatory practice, community development and environmental sustainability. Creating a dynamic between theoretical discourse and a practical hands-on building project, the Summer School focused on the importance of addressing the complexities of context, culture and community in development, and the potentially negative effects of remedial aid when this does not take these factors into account (Berg, 2008, p. 79).
\end{abstract}

Sas-Bojarska and Rembeza (2020) explain that their workshop series organized between Portugal and Poland presented different local problems. These 'real' problems range from investment pressure, city fragmentation, degradation of landscape, changes in underground water level, pollution (air, noise, vibrations), chaotic-mix/use, and architectural banality (Sas-Bojarska \& Rembeza, 2020, p. 191). These problems of a contemporary city turn out to be common problems affecting all the cities in subsequent years, especially European ones. This relevance stems from their selection of design areas based on "the complexity of problems, the challenges, and potential for creating new city values (Sas-Bojarska \& Rembeza, 2020, p. 195)."

In place-based studios, learning from the place and its people is paramount. Ethnographic, demographic, social statistical, site analysis, and participant-observation measures are among the methods here. These interactions with the community move the learning into the context.

When learning takes place in the community, working alongside local partners, the process can be empowering, participatory and more meaningful. Field based learning allows for complex problems to be approached from a number of angles in order to see the short-term and long-term implications, and the range of stakeholders involved. The perception of this complexity changes once one is able to break down the challenges into a process consisting of people and responsibilities (Ernst \& Edwards, 2013, p. 99).

Place-based learning practices require workshop participants to have intense interactions with the community, including their invitation to the final presentation and discussion sessions (Twardoch \& Stangel, 2016).

\subsubsection{Pre-defined design problem/conceptual question}

These workshops challenge participants with a pre-defined design problem or conceptual approach. The workshop entitled "COVID-19 Challenges: Architecture of Pandemic" (Milovanovic et al., 2020) and the "Gazi University Winter Schools" best illustrates this approach (Paszkowski \& Gołebiewski, 2020).

\footnotetext{
${ }^{8}$ INTBAU's summer school are still organized. Please see: https://engelsberg.intbau.org

${ }^{9}$ Official page of ASF-UK: http://www.asf-uk.org
} 
3.2.2.3 Exploring (Material/Techniques; City; Heritage; Use of computational design and fabrication processes)

Various workshop organizations explore the potentials of materials by delving into new fabrication techniques and form generation processes (Guner et al., 2017; Orhan, 2017; Tang, 2013). Another theme focuses on exploring the city while aiming to immerse students in context.

Page | 53 These workshops expect to derive new design interventions in the city, enhance students' ability to read the city based on architectural interpretations (Polatoğlu \& Vural, 2012; Umran Topcu \& Taberna Torres, 2018; Turgut \& Canturk, 2015). Exploring cultural or modern heritage is seen to be an emerging theme. (Jimenez Delgado \& Piedecausa-Garcia, 2013; Kuyrukcu \& Kuyrukcu, 2015; Pereira \& Roche, 2016). These workshops focus on developing either preservation or reuse of modern or cultural heritage by making direct documentation. Exploring computational tools' use and potentials is an emerging workshop theme (Cabral Filho, 2005; Karadağ \& Tuker, 2020; Sorguç et al., 2019).

\subsubsection{Learning-By-Doing: Studio Model}

Most ISADs are built upon design studios enabling students' active experimentation while incorporating all the learning modes. Learning by working on 'unique' problems (Kahvecioglu et al., 2002), students actively incorporate all the learning modes. All the workshops pursued group supervision, including desk-crits or panel crits, in terms of instructional methods. This study classified ISADs based on the studio actual outputs:

(1) Hands-on learning with design-build or fabricate projects

(2) Studios resulting with architectural design projects/proposals represented with diverse mediums

(3) Studios resulting in architectural reflections.

\subsubsection{Design Studio: Hands-on (Design-build and Design-fabricate)}

Design-build workshops are studio models in which "participants actually materialise their conceptual designs in either prototypes or full-scale models (Shatarova, 2015)." The material and materiality (process) of architecture is mostly reflected in these types of studios. In these studios, students first develop a design model and build the project. Hence knowledge is explained to be assimilated better through the first-hand experience (Garcia Saez et al., 2016; Guner et al., 2017). Especially construction workshops reinforce theory courses by taking learning out of classrooms and textbooks to develop structural intuition while working with physical models (Tang, 2013).

In the mapping, the study separated this studio model into two categories to differentiate between building technologies used in the workshop: Design-build and design-fabricate. While design-to-fabricate workshops allow students to explore the potentials of computational design processes combined with new fabrication technologies "to make automated construction a reality (Shi et al., 2020)", most design-build workshops are organized for communities with low income affected by political and natural disasters living in rural areas that are not accessible to architectural services. In these workshops, sustainable, recyclable, or salvaged materials can be obtained locally, easily, and cheaply (Guner et al., 2017, p. 6868).

\subsubsection{Design Studio (Speculative): Architectural Representations, Models, Inspirations}

These studios include architectural design exercises using architectural representation techniques, such as models, renders, etc. (Cabral Filho, 2005; Sorguç et al., 2019; Tzaka et al., 2010).

\subsubsection{Studio: Experimental / Reflective Practice}

This type of studios usually has a theme this study calls 'exploring city.' Students learn-byexperiencing certain urban settings and buildings detailed below. In these workshops, students 
learn by reflective observation because they are asked to articulate their reflections on their experience via diverse mediums or techniques, like urban sketches, stop-motion videos (Umran Topcu \& Taberna Torres, 2018), photographs accompanied with literary texts (Kahvecioglu et al., 2002), or diaries (Symans et al., 2010).

\title{
3.2.4 Learning-By-Travelling/Living/Exploring the Place
}

Learning by exploring the place or immersing in the cities is an educational tool used by ISADs for several objectives. First, they make "both students and professionals aware of this whole other world outside their studio design (Berg, 2008, p. 83)." Second, participants, either by researching the field or only by spending time in the new context, can grasp the meaning of lived space and the community. The following excerpts from reviewed publications better illustrate this learning experience:

\begin{abstract}
We explained the relevance of feeling with the cities. We encouraged the students not just to walk, but to live the places and buildings [...] We challenged the groups for trying to find this lived space, these personal feelings they had while they were going around different places (U. Topcu et al., 2015, p. 262).

Meetings, communication with locals, lunches and study took place all at the site so that students are conducted in the area to experience a longer period of time, to monitor the behaviors of local people, to perceive the use of space. One of the most important aims of these workshops was to gather students together from different cultures (Polatoğlu \& Vural, 2012, p. 483).
\end{abstract}

This lived space provides learning-by-experiencing.

\section{ISAD Outputs}

Workshop outputs become three sources of inspiration: Place, future-ongoing research activities, innovations toward formal learning practices.

\subsection{Place: An Inspiration and A Facilitator}

Place-based workshops in architecture and urban planning potentially bring benefit not only for practicing students but also for the world around them as they are mainly concerned with socially relevant issues. The primary objective of these workshops is to explore the "real problems" of the built environment. Workshop outputs may not be fully elaborated for a direct professional application, given the students' lack of experience or idealistic approach. However, the workshop is a "spark, an inspiration for further actions, a great opportunity for public education for all and urban-related issues awareness of building (Twardoch \& Stangel, 2016)." Studied papers document how certain workshops have become inspirations for future actions (Sas-Bojarska \& Rembeza, 2020; Twardoch \& Stangel, 2016). Berg (2008) explains the impact of ASF-UK Summer School as follows:

A live hands-on building programme using waste material simulated resettlement and reconstruction, and explored the ways and means of building local capacities for preparedness and recovery (Berg, 2008).

Workshops are considered as a catalyst within a long-term agenda for socially active design and build activities (Ernst \& Edwards, 2013).

\begin{abstract}
The success of the model/pedagogy can be critically evaluated against the success of this workshop to instigate and sustain a longer-term project. The longer-term programme is the only way to achieve meaningful engagement, positive change and sustained learning. While the workshop is only two weeks the fast-paced learning scenario, with skilled individuals from seven nationalities and a variety of backgrounds and experiences, can provide the momentum to drive forward a process (Ernst \& Edwards, 2013).
\end{abstract}

Skills gained in a digital art workshop are seen to have triggered students in engaging new activities in support of a series of workshops with the homeless group. 
In order to facilitate the participatory design process, they had to envisage an interface to evaluate the ability of lay people in the use computers; they had to set up a multi-functional web page; they had to sort out network issues in order to make one interface working across a dozen computers. Moreover, what is remarkable is that they were able to achieve these tasks by transferring the technical and creative knowledge they had developed in an otherwise playful situation, related to digital art (Cabral Filho, 2005).

However, Ernst and Edwards (2013) suggest that these workshops "take place under the aegis of foundations, NGOs, universities and other bodies ready to continue the work's outcomes" for furthering the workshop outcomes and long-lasting interest in the topic.

\subsection{Research and Education: Inspirations}

Workshops are both a catalyst for ongoing research activities and a spark for future research. Their outcomes are visible faster, and outcomes are tangible (Smatanová \& Dubovcová, 2016).

Cyborg sessions organized to address women's inequality in technology at the lowa State University exemplifies such a role. Through these sessions, researchers test a pedagogical program's viability that provides a supportive environment and opportunities for women (Doyle et al., 2018). Diniz (2015) organizes a workshop for testing her hypothesis of using prototypes as the primary vehicle for research through design. Karadağ and Tuker (2020) organize an ecology-based computational design workshop to understand whether the incorporation of computational thinking into the design process would "increase students' awareness of the ecological dimension and their ability to make this dimension an integral part of their projects (2020)." All these applications correlate with the role of workshops in updating/renewing the existing formal learning environments. The following section will detail this issue further. These workshops also allow students to become part of ongoing research.

"I International Planning Preservation Workshop" is explained to lead to establishing a permanent international work structure for the development of projects of the Historical City. Afterward, this network published several books that refer to this workshop and teaching proposals shared between the affiliated institutions (Jimenez Delgado \& Piedecausa-Garcia, 2013). By the same token, Ernst \& Edwards (2013) reports how an international workshop coordinated by ASFUK and SEEDS India paved the way for "a new three-year project to promote appropriate shelter technologies and processes for disaster and climate resilience in the Himalayan Region (2013, p. 101). Orozco-Messana et al. (2020) explain how "ISAlab Workshops" have become an initiator of new master thesis research.

Tzaka et al. (2010) point out how the experimentations in the "SKG_Flux" on parametric urban design have relevance to developing the ways, the contents, and forms of expression of the parametric approach to urban design are converted into teaching practices and educational outcomes. Cabral Filho (2005) accounts for the role of a series of experimental workshops to include an artistic approach to the work in a computer lab dedicated to teaching and researching architecture. Shi et al. (2020) organized four "Robotic Tectonics" workshops to develop a new didactic pedagogical approach that relies on robotic tectonics principles.

Among the reviewed workshops, the study determined that problem-based learning workshops are an ideal mix of practice, research, and education and balance "situations in which the transfer of practice into faculty programs influences the development of education in the form of an architecture office where educational criteria do not take priority (Momirski, 2019)."

\subsection{Education: Students' Skills}

Reviewed studies detail the objectives of workshops concerning the students' learning outcomes. Given the diversity of workshop themes, the competences, skills, and abilities provided by each workshop differ from one another. Almost all the reviewed workshops address the acquisition of the knowledge, skills, and competences defined by Article 46 of 2013/55/EU entitled 
"Training of architects" (The European Parliament and of the Council of the European Union, 2013, p. 55). This study reveals that:

- Place-based workshops enhance the "understanding of the relationship between people and buildings, and between buildings and their environment, and of the need to relate buildings and the spaces between them to human needs and scale," owing to its high focus on the context and communities.

- Workshops pursuing hands-on learning practices provide "the understanding of the structural design, and constructional and engineering problems associated with building design."

- One reviewed workshop (Cabral Filho, 2005) was specially dedicated to understanding how the knowledge of fine arts as an influence on the quality of architectural design has an impact on the design outcome. Numerous fine art techniques (stop-motion videos, collage techniques, etc.)

- Numerous workshops aim to foster students' skills in addressing sustainability issues both on urban and building scales. Beyond providing "adequate knowledge of physical problems and technologies and the function of buildings so as to provide them with internal conditions of comfort and protection against the climate, in the framework of sustainable development," we observe that place-based workshops focus also on skills and knowledge in addressing social sustainability. Another growing workshop strategy is the use of computational tools in designing environmental sensitive projects.

- All the reviewed workshops require students to work in teams. This strategy develops not only students' communication skills but also interpersonal skills via group work.

Apart from these aspects, international workshops enhance students' self-confidence in international environments and language proficiency (Orhan, 2017; Umran Topcu \& Taberna Torres, 2018, 2018).

5. Mapping and Analysis of Short-Term Architectural Design Studios: Visualizing the Field: Quantitative Analysis of Isads

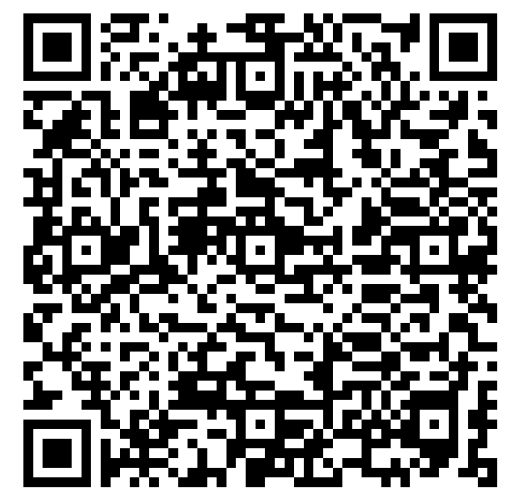

Figure 3 Please scan this QRCODE to access the interactive visualization (Ruhi Sipahioğlu et al., 2021) ${ }^{10}$

The second stage involved expanding the pool of past ISADs. The study pursued four strategies in reaching information about past ISADs: (1) Previous ISADs conducted by the MATERIART project partner institutions (2020); (2) Websites of past ISADs; (3) Research papers on ISADs from the project conference (Couceiro da Costa et al., 2019); (4) ISADs retrieved from the scoping study. The study analyzed 47 ISADs in total. Out of 47 ISADs, two were held via distance learning, and the

\footnotetext{
${ }^{10}$ This interactive visualization is prepared by the authors via the Tableau Desktop (Professional Edition). In the remainder \#[number] represents the figures in the online map. To access the interactive:

https://public.tableau.com/profile/isilsipahioglu\#!/vizhome/OutsidetheschoolAreviewofthenon-formalshort-

termarchitecturalworkshops/FINALSTORY
} 
remaining was face-to-face activity. \#1 depict the distribution of the number of workshops across the countries in which a workshop is held.

Table 5 Number of workshops based on data source

\begin{tabular}{|l|l|}
\hline Source & Number of Workshops \\
\hline Previous ISADs conducted by the project partner institutions & 2 \\
\hline Websites of past ISADs & 15 \\
\hline Research papers on ISADs from the project Conference 2019 & 3 \\
\hline ISADs retrieved from the scoping study & 27 \\
\hline
\end{tabular}

The study combined qualitative and quantitative analysis methods to map the principles and outputs of ISADs. Based on a qualitative approach, it coded each ISAD with the codes and themes determined by the scoping study results and prepared a spreadsheet (Table 6) based on the data extraction table produced at the 4th stage of the scoping study (Appendix B). Subsequently, the study used the data visualization software, Tableau Desktop, mostly used in big data analytics, owing to its ease in providing new perceptions from data and enabling an interactive analysis framework (Figure 4). To make the following analysis:

(1) Quantitative analysis of ISADs (Geographical distribution; outputs; principles, as elements creating the atmosphere and tactics);

(2) Qualitative analysis to reveal the impact of workshop outputs on the stakeholders.

Table 6 Data extraction chart for ISADs

\begin{tabular}{|c|c|c|c|c|}
\hline \multicolumn{3}{|c|}{ Extracted data } & \multicolumn{2}{|c|}{ Description } \\
\hline \multicolumn{3}{|c|}{ Workshop Name } & \multicolumn{2}{|c|}{ The name of the workshop } \\
\hline \multicolumn{3}{|c|}{ Source } & \multicolumn{2}{|c|}{ Website link; scoping study reference } \\
\hline \multicolumn{3}{|c|}{ Workshop Type } & \multicolumn{2}{|c|}{ Short-term workshop / winter school / summer school } \\
\hline \multicolumn{5}{|c|}{ Year Started } \\
\hline \multicolumn{3}{|c|}{ Year Ended (If relevant) } & \multicolumn{2}{|c|}{ End year of workshop series (if relevant) } \\
\hline \multicolumn{3}{|c|}{ Partners } & \multicolumn{2}{|c|}{ Name of partner organizations } \\
\hline \multicolumn{3}{|c|}{ Country } & \multicolumn{2}{|c|}{ The country where the workshop is organized. } \\
\hline \multirow{2}{*}{ 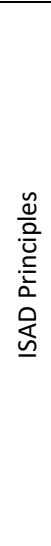 } & 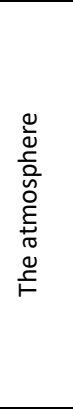 & Duration & $\begin{array}{l}0 \\
0 \\
0 \\
0 \\
0\end{array} \quad$ & $\begin{array}{l}\text { 1-4 DAYS } \\
\text { 5-10 DAYS } \\
\text { 10-15 DAYS } \\
\text { 15-30 DAYS } \\
31 \text { OR LONGER }\end{array}$ \\
\hline & ס & Theme & \multicolumn{2}{|c|}{$\begin{array}{l}\text { Experimental / Reflective; Problem-based (real problems); experimental for research } \\
\text { for ongoing research }\end{array}$} \\
\hline
\end{tabular}

${ }^{11}$ These categories are taken from the categorization applied in the ERASMUS+ programme application documents. 


\begin{tabular}{|c|l|l|}
\hline \multirow{3}{*}{} & Learning-by-doing & $\begin{array}{l}\text { Hands-on learning (Design-build/fabrication); Design Studio: Architectural } \\
\text { Representations, Models, Inspirations; Architectural Reflections }\end{array}$ \\
\cline { 2 - 3 } & Lectures & YES or NO (indicates whether workshops include lectures) \\
\cline { 2 - 3 } & $\begin{array}{l}\text { Learning-by- } \\
\text { traveling/living }\end{array}$ & Indicates whether the workshop program includes technical visits. \\
\cline { 2 - 3 } & Community Engagement & $\begin{array}{l}\text { YES or NO (indicates whether workshop outputs or process involves local community } \\
\text { or citizens) }\end{array}$ \\
\hline \multirow{3}{*}{$\begin{array}{c}\text { ISAD } \\
\text { Outputs }\end{array}$} & Place & Indicates whether workshop outputs have an impact on the local community \\
\cline { 2 - 3 } & Research and Education & $\begin{array}{l}\text { Indicates whether workshop outputs have an impact on future/ongoing research } \\
\text { agenda, including research on architectural education }\end{array}$ \\
\cline { 2 - 3 } & Addressed Skills & $\begin{array}{l}\text { Classified according to the competences, skills, and abilities skills defined in Article 46 } \\
\text { of 2013/55/EU entitled “Training of architects." }\end{array}$ \\
\hline
\end{tabular}

\subsection{Mapping the Atmosphere}

The study does not attempt to make statistical analysis, but it deduces several remarks based on the cross-tabulation of these three sets of data given in the Tables below.

Table 7 The number of workshops across workshop type

\begin{tabular}{|l|l|}
\hline Workshop Types & Number of Workshops \\
\hline Festival & 1 \\
\hline Short-Term Workshop & 29 \\
\hline Summer School & 9 \\
\hline Summer Workshop & 5 \\
\hline Winter Workshop & 3 \\
\hline
\end{tabular}

Table 8 The number of workshops across workshop participants' nationalities

\begin{tabular}{|l|l|}
\hline Participants' nationalities & Number of Workshops \\
\hline International & 28 \\
\hline National & 19 \\
\hline
\end{tabular}

Table 9 The number of workshops across workshop participants' disciplines

\begin{tabular}{|l|l|}
\hline Participants' disciplines & Number of Workshops \\
\hline Monodisciplinary & 25 \\
\hline Multidisciplinary & 22 \\
\hline
\end{tabular}

Table 10 The number of workshops across workshop duration

\begin{tabular}{|l|l|}
\hline Participants' disciplines & Number of Workshops \\
\hline 1-5 Days & 16 \\
\hline 6-10 Days & 16 \\
\hline 11-15 Days & 14 \\
\hline $16-30$ Days & 1 \\
\hline
\end{tabular}

Compared to monodisciplinary ISADS, a considerable number of 11-15 days workshops are multidisciplinary. In terms of duration, the nationality of participants does not show a significant difference. What is more striking is that out of 28 international ISADs, 19 are multidisciplinary, while in national ISADs out of 19 , only three are multidisciplinary (\#2).

\subsection{Mapping the Tactics}

The second set of data pertain to the mapping of workshop themes and teaching/learning methods (learning-by-doing). Learning-by-travelling is intentionally not included in this analysis because the scoping study indicated that most ISAD programs include technical city tours. As for lectures, out of 47 ISADs, only five did not include lectures (\#3).

Table 11 Tables representing the number of workshops across ISAD tactics: Studio methods

\begin{tabular}{|l|l|}
\hline Studio Methods & Number of Workshops \\
\hline Architectural Reflections & 10 \\
\hline Design Studio (Speculative) & 21 \\
\hline Design Studio: Hands-on (Design-build) & 10 \\
\hline Design Studio: Hands-on (Design-fabricate) & 5 \\
\hline Multiple & 1 \\
\hline
\end{tabular}


Table 12 Tables representing the number of workshops across ISAD tactics: Themes

\begin{tabular}{|l|l|}
\hline Themes & Number of Workshops \\
\hline Exploring: City & 7 \\
\hline Exploring: Heritage & 5 \\
\hline Exploring: Material/Techniques & 9 \\
\hline Exploring: New Representation Techniques & 1 \\
\hline Exploring: Use of computational tools & 7 \\
\hline Learning-by-travelling & 1 \\
\hline Multiple Themes (architecture, design, food, fashion) & 2 \\
\hline Pre-defined design problem/conceptual question & 5 \\
\hline Real problems & 10 \\
\hline
\end{tabular}

The studio model 'Architectural reflections' focuses on exploring cities through various representation mediums, ranging from sketching, stop-motion videos, photography, etc. Hands-on learning via build-design workshops explores the potentials of materials, like gypsum, concrete, or timber.

In terms of the learning environment, 'real problems' are seen to be studied in multidisciplinary teams. While exploring the city is a theme dedicated to architecture students (\#4). The majority of ISADs up to 5 days long pursued 'architectural reflections' models. Through the interactive tableau visuals, it is possible to explore the diverse array of ISAD durations (\#5).

Design-Fabricate studios are seen to have no direct contact with the community while remaining detached from the local community (\#6).

\subsection{Mapping the Outputs}

The scoping study showed how a workshop might have diverse outputs beyond the actual ones (either built or designed). These outputs relate to three major categories: Place (either workshop hometown or the assigned place); Education (Formal); Research. The figures \#7 and \#8 represent the correlation between the studio model/theme and education/research, studio model/theme, and place.

Workshops on the use of computational design and fabrication tools are means of developing new formal education strategies. However, until today it is not possible to interact with the broader community in which the workshop is organized. Figures \#9 and \#10 represent the cross-tabulations of studio models and their impact on the place, research, and education. This analysis depicts that the design studio (speculative) model has become a means to support the research-by-design strategy. At the same time, design-build studios enhance students' understanding of the potentials of the material. One can make diverse interpretations based on the tableau visualization; therefore, the online table includes the details of all the analyzed ISADs and their references.

\section{Un-Conclusion(s)}

Workshops, including their processes and outputs, are an inspiration for the knowledge triangle of the field of architecture. Workshops hold two crucial roles: (1) A research-by-design activity to address socio-economic-ecological problems caused by the built environment; (2) A pioneer activity in improving curricula and teaching-and-learning practices.

This study foresees the potential of ISADs in overcoming time-related, geographical, economic limitations; in providing fresh perspectives on content and methods concerning architectural education; expanding the intellectual resources of students; enabling international collaboration between diverse institutions; breeding an experimental/flexible learning and research environment in the 1st and 2nd cycles to absorb ever-changing tools/methods promoted in professional/research sides of the field promoting the pedagogical update of studio tutors, including professional practitioners, with peer teaching methods. 
The field requires enhancing the visibility of workshop process and results combined with regular reporting on workshop activities to raise awareness building among future professionals and the wider public. Hence, beyond doing a review of existing ISADs, this output provides the reader with an array of diverse teaching and learning practices in these non/informal grounds. The interactive mapping created via Tableau is a tool open for interested parties in accessing previous ISADs.

\section{Acknowledgement}

We would like to thank Nur Çağlar (TOBB ETU) for her expert advice and encouragement throughout the MATERIART project. This paper is a shortened version of the project output "Architectural Design Studio Inspirations: Alternative Pedagogies" of the project entitled "Art and Science of Materiality in Architectural Design Education (MATERIART) (2017-1-TR01-KA203046280), which was funded by the Erasmus+ Program of the European Union.

\section{References}

Balaid, A., Abd Rozan, M. Z., Hikmi, S. N., \& Memon, J. (2016). Knowledge maps: A systematic literature review and directions for future research. International Journal of Information Management, 36(3), 451-475. https://doi.org/10.1016/j.ijinfomgt.2016.02.005

Braun, V., \& Clarke, V. (2006). Using thematic analysis in psychology. Qualitative Research in Psychology, 3(2), 77-101. https://doi.org/10.1191/1478088706qp063oa

Brooks-Harris, J. E., \& Stock-Ward, S. R. (1999). Workshops: Designing and facilitating experiential learning. SAGE Publications, Inc.

Cabral Filho, J. dos S. (2005). Digital Art-A Field of Inquiry for Contemporary Architecture. International Journal of Architectural Computing, 3(3), 355-372. https://doi.org/10.1260/147807705775377276

Ciravoğlu, A. (2003). Mimari tasarım eğitiminde formel ve enformel çalışmalar üzerine [On formal and informal studies in architectural design education]. Yapı, 257, 43-47.

Couceiro da Costa, M., Formiga, B. \& Abbas, G. M. (Eds.) (2019). Materiality as a process. Caleidoscopio.

Diniz, N. (2015). The anatomy of a prototype: Situating the prototype and prototyping on design conceptual thinking. In L. Combs \& C. Perry (Eds.), Computational ecologies : design in the anthropocene : ACADIA 2015, October 19-25, Cincinnati_Ohio: exhibition catalog of the 35th annual conference of the Association for Computer Aided Design in Architecture (ACADIA) (pp. 323-332). ACADIA. http://papers.cumincad.org/data/works/att/acadia15_323.pdf

Doyle, S., Forehand, L., Hunt, E., Loughrey, N., Schneider, S., \& Senske, N. (2018). Cyborg sessions: A case study for gender equity in technology. In T. Fukuda, W. Huang, P. Janssen, K. Crolla \& S. Alhadidi (eds.), Learning, adapting and prototyping - Proceedings of the 23rd CAADRIA Conference (pp. 71-80). The Association for Computer-Aided Architectural Design Research in Asia (CAADRIA). http://papers.cumincad.org/data/works/att/caadria2018_259.pdf

Ernst, S., \& Edwards, A. (2013). Reducing risk and promoting sustainability in the foothills of the Himalayas: A Pedagogy for Teaching and Practicing Sustainable Development. Archnet-IJAR: International Journal of Architectural Research, 7(3), 93-107.

Fernandez-Antolin, M.-M., del Rio, J. M., \& Gonzalez-Lezcano, R.-A. (2020). The use of gamification in higher technical education: Perception of university students on innovative teaching materials. International Journal of Technology and Design Education. https://doi.org/10.1007/s10798-020-09583-0

Garcia Saez, M. S., Tomas Marquez, S., La Spina, V., Mileto, C., \& Vegas Lopez-Manzanares, F. (2016). Learning by doing of traditional construction techniques: Gypsum flooring. In L.G. Chova, A.L. Martinez \& I.C. Torres (Eds.), INTED2016 Proceedings (pp. 1684-1689). IATED.

Guner, A. F., Benli, G., Karacar, P., \& Kasapseckin, M. A. (2017). Design-build workshops in architectural education: A case study, adobe bus stop in northern cyprus. In L.G. Chova, A.L. Martinez \& I.C. Torres (Eds.), EDULEARN17 Proceedings (pp. 6868-6876). IATED.

Habraken, N. J. (2006). Questions that will not go away: Some remarks on long-term trends in architecture and their impact on architectural education. Open House International, 31(2), 12-19.

Hardy, M. (2008). Experiments in traditional building, architecture and urbanism education: INTBAU's recent work. In S. Roaf \& A. Bairstow (Eds.), Oxford Conference: A Re-evaluation of education in architecture (pp. 405-410). WIT Press. 
Jimenez Delgado, A., \& Piedecausa-Garcia, B. (2013). Teaching-learning process of historical heritage: A journey as a beginning, path and end. In L.G. Chova, A.L. Martinez \& I.C. Torres (Eds.), EDULEARN13 proceedings (pp. 5321-5326). IATED.

Kahvecioglu, H., Erdem, A., \& Paker-Kahvecioglu, N. (2002). Short term workshop: An alternative strategy in architectural design education. In D. Marjanovic (Ed.), DESIGN 2002: Proceedings of the 7th International Design Conference, Vols 1 and 2 (pp. 997-1001).

Karadağ, D., \& Tuker, C. (2020). A proposal for a computational design and ecology based approach to architectural design studio. International Journal of Technology and Design Education. https://doi.org/10.1007/s10798-020-09594-x

Kuyrukcu, Z., \& Kuyrukcu, E. Y. (2015). An educational tool the importance of informal studies/studios in architectural design education: A workshop summary. Procedia-Social and Behavioral Sciences, 174, 2666-2673. https://doi.org/10.1016/j.sbspro.2015.01.950

Levac, D., Colquhoun, H., \& O’Brien, K. K. (2010). Scoping studies: Advancing the methodology. Implementation Science, 5(1), 69. https://doi.org/10.1186/1748-5908-5-69

MATERIART (2020). Art and Science of Materiality in Architectural Design Education. https://www.materiart.org

Milovanovic, A., Kostic, M., Zoric, A., Dordevic, A., Pesic, M., Bugarski, J., Todorovic, D., Sokolovic, N., \& Josifovski, A. (2020). Transferring COVID-19 challenges into learning potentials: Online workshops in architectural education. Sustainability, 12(17). https://doi.org/10.3390/su12177024

Momirski, L. A. (2019). Urban design workshops in the education curriculum: Advantages and disadvantages. IOP Conference Series: Materials Science and Engineering, 471(10). https://doi.org/10.1088/1757$899 X / 471 / 10 / 102048$

Orhan, M. (2017). The role and importance of workshops in the architectural design education; Case of "Self Made Architecture I-II. New Trends and Issues Proceedings on Humanities and Social Sciences, 3, 131136. https://doi.org/10.18844/gjhss.v3i3.1545

Paszkowski, Z. W., \& Gołebiewski, J. I. (2020). International design workshops as an intensive form of architectural education. World Transactions on Engineering and Technology Education, 18(1), 51-56.

Pereira, S. M., \& Roche, J. (2016). Across disciplinary and national borders: A pedagogical tool for reuse. In A. Tostoes \& Z. Ferreira (Eds.), Proceedings of the 14th International Docomomo Conference - Adaptive Reuse: The Modern Movement Towards the Future (pp. 854-860). Docomomo.

Polatoğlu, Ç., \& Vural, M. (2012). As an educational tool the importance of informal studies/studios in architectural design education; Case of walking İstanbul 1\&2. Procedia-Social and Behavioral Sciences, 47, 480-484. https://doi.org/10.1016/j.sbspro.2012.06.684

Ruhi Sipahioğlu, I., \& Alanlı, A. (2020). A Threshold in-between Education and Profession: The Final Architectural Design Studio. In N. Çağlar, I. G. Curulli, I. Ruhi Sipahioğlu, \& L. Mavromatidis (Eds.), Thresholds in Architectural Education. Wiley-ISTE. doi:10.1002/9781119751427.ch7

Ruhi Sipahioğlu, I., Öztoprak, Z., Yılmaz, B., \& Çağlar, N. (2020). The Dialogy of Architectural Design Studio and Learning Milieux. In V. Trova \& I. Lykourioti (Eds.), Materiality in the architectural studio process: Good practices (pp. 36-53). Caleidoscópio.

Ruhi Sipahioğlu, I., Abbas, G.M., \& Sönmez, B. (2021). Outside the school: A review of the non-formal shortterm architectural workshops. [Visualization]. https://public.tableau.com/views/OutsidetheschoolAreviewofthenon-formalshorttermarchitecturalworkshops/FINALSTORY?:language=en\&:display_count=y\&:origin=viz_share_link

Sas-Bojarska, A., \& Rembeza, M. (2020). International architectural-urban-landscape design workshops to strengthen students' education, capabilities and mobility. World Transactions on Engineering and Technology Education, 18(2), 190-196.

Shatarova, R. (2015). The commune as an alternative learning experience in architectural education: The case of EASA (European Architecture Students Assembly). In F. Uslu (Ed.), ADVED 15: International Conference on Advances in Education and Social Sciences Abstracts \& Proceedings (pp. 730-740). Ocerint Publishing.

Shi, X., Fang, X., Chen, Z., Phillips, T. K., \& Fukuda, H. (2020). A didactic pedagogical approach toward sustainable architectural education through robotic tectonics. Sustainability, 12(5), 1757. https://doi.org/10.3390/su12051757

Smatanová, K., \& Dubovcová, A. (2016). Workshop as a tool in architectural education. World Transactions on Engineering and Technology Education, 14(1), 123-128.

Sorguç, A. G., Yemiscioglu, M. K., \& Ozgenel, C. F. (2019). A computational design workshop experience for 21st century architecture education. In J.P. Sousa, G.C. Henriques \& J.P. Xavier (Eds.), ECAADE SIGRADI 
2019: Architecture in the age of the 4th industrial revolution (pp. 127-136). eCAADe. https://doi.org/10.5151/proceedings-ecaadesigradi2019_353

Symans, M., Mistur, M., \& Danziger, B. (2010, June). Facilitating collaboration of engineering and architecture students via an international travel-study workshop [Paper presentation]. 2010 Annual Conference \& Exposition, Louisville, Kentucky.

Tang, G. (2013). Timber gridshells: Beyond the drawing board. Proceedings of Institution of Civil Engineers: Construction Materials, 166(6), 390-402. https://doi.org/10.1680/coma.12.00046

Tanyeli, U. (2013). Why Cannot (Even) Architectural Education Be Flexible in Turkey? In S. Lökçe, O. Turan, \& B. B. Hisarligil (Eds.), MIMED Forum IV: Flexibility in Architectural Education (pp. 77-88). Cambridge Scholars Publishing.

The European Parliament and of the Council of the European Union. (2013). Directive 2013/55/EU of the European Parliament and of the Council. Official Journal of the European Union, 132-170.

Topcu, U., Taberna, J., \& Hofert, K. (2015). A visual tale of two cities: Video as a tool for representation through informal learning. In D. Garcia-Escudero \& B. Bardi i Mila (Eds.), III workshop on educational innovation in architecture (JIDA'15) (pp. 255-265). UPC.

Topcu, Umran, \& Taberna Torres, J. (2018). Multicultural education in Barcelona. In L.G. Chova, A.L. Martinez \& I.C. Torres (Eds.), 12TH INTED proceedings (pp. 2777-2785). IATED.

Turgut, H., \& Cantürk, E. (2015). Design workshops as a tool for informal architectural education. Open House International, 40(2), 88-95. https://doi.org/10.1108/OHI-02-2015-B0012

Twardoch, A., \& Stangel, M. (2016). Beyond the university: Socially engaged student's workshops on public space and housing. In M. Perinkova \& M. Nedved (Eds.), 8th Architektura v Perspektiv 2016 (pp. 23-25). Technicka univerzita Ostrava.

Tzaka, A., Kalogirou, N., Papakostas, G., \& Symeonidou, I. (2010). SKG IN_FLUX: An urban 'process-plan'. In G. Schmitt, L. Hovestad, L. VanGool, F. Bosche, R. Burkhard, S. Coleman, J. Halatsch, M. Hansmeyer, S. KonsorskiLang, A. Kunze \& M. SehmiLuck (Eds.), ECAADE 2010: Future cities (pp. 107-114). ETH Zurich; Autodesk; BASF; Bentley; IBM.

Tzonis, A. (2014). Architectural education at the crossroads. Frontiers of Architectural Research, 3(1), 476478. https://doi.org/10.1016/j.foar.2014.01.001

Ucci, M., Law, S., Andrews, R., Fisher, A., Smith, L., Sawyer, A., \& Marmot, A. (2015). Indoor school environments, physical activity, sitting behaviour and pedagogy: A scoping review. Building Research \& Information, 43(5), 566-581. https://doi.org/10.1080/09613218.2015.1004275

UNESCO Institute for Lifelong Learning. (2012). UNESCO Guidelines on the Recognition, Validation and Accreditation of the Outcomes of Non-formal and Informal Learning. UNESCO Institute for Lifelong Learning. https://unesdoc.unesco.org/ark:/48223/pf0000216360_eng

Berg, H.v.d. (2008). (Re-)building communities: A case study in architectural education. Open House International, 33(2), 78-84. https://doi.org/10.1108/OHI-02-2008-B0010

Yang, J. (2015). Recognition, validation and accreditation of non-formal and informal learning in UNESCO member states. UNESCO Institute for Lifelong Learning.

\section{Resume}

Işıl Ruhi Sipahioğlu, Architect, is a lecturer at TOBB University of Economics and Technology, Department of Architecture. She received her bachelor's degree in architecture from Gazi University (2005); her master's degree in architecture from Middle East Technical University (METU) (2008); and her Ph.D. degree in Building Environment and Technology Program at Politecnico di Milano (2013). At TOBB ETU, she teaches the final architectural design and works on research projects on Architectural Education and climate change. Her research interests include sustainable building design and assessment and architectural education.

Günsu Merin Abbas, a full-time lecturer at TOBB University of Economics and Technology, Department of Architecture, holds a B.Arch. from Izmir University of Economics (2011) and M.Arch. from METU (2014), where she conducts her Ph.D. studies. In line with her studies, she has also taken part in office practice focusing on hospital and institutional building projects, as well as a number of international freelance projects focusing on computational façade design. Her research interests are design computing, performative architectural design, tooling, and emergent technologies. Günsu teaches 2 nd year drawing and representation courses by employing BIM and performative design tools and aims at implementing BIM and performative design understanding to the existing curricula, as well as elective courses on computational design. 
Burçin Yılmaz graduated from the Faculty of Engineering and Architecture at Gazi University in 2010. During her bachelor, she took part in several workshops and carried out internships in various design offices in Ankara. After her Bachelor, she worked at design offices for two years and established her own company in 2012. She acquired her master's degree from TOBB University of Economics and Technology in 2017. Thereafter, she taught as adjunct staff in the design studio courses at TOBB ETU. Currently, she is developing her doctoral research in the department of the Built Environment at Eindhoven University of Technology. 